\title{
Complementary Food Consumption of Canadian Infants
}

\author{
James K. Friel*, Corinne A. Isaak, Rhona Hanning and Angela Miller \\ Departments of Human Nutritional Sciences and Pediatrics, University of Manitoba, Winnipeg, Manitoba, Canada R3T \\ 2N2, Department of Health Studies \& Gerontology, University of Waterloo, Ontario N2L 3G1, Canada
}

\begin{abstract}
In July, 2003, a cross-sectional survey was conducted by Heinz Canada, on a nationally representative sample of mothers with infants aged three to 12 months. The surveys mailed to new mothers consisted of 1) a questionnaire to assess demographic information and 2) a four day food diary, providing dietary data for nearly 2,951 infants. The initiation rate of breastfeeding was $73 \%$ for study infants. At three months, $81 \%$ of the infants received complementary foods (mostly cereal, fruits, and vegetables, but some had also been introduced to meats, dairy products, and mixed dishes). These data suggest a current pattern for the early introduction of complementary foods, some by three months and the majority by six months of age. The World Health Organization (WHO) and Health Canada now recommend exclusive breastfeeding until six months of age. The impact this recommendation may have on the feeding pattern of Canadian infants remains to be seen.
\end{abstract}

Keywords: Complementary feeding, infant nutritional physiology, supplementary feeding.

\section{INTRODUCTION}

In 2001, the World Health Organization (WHO) [1] issued a global recommendation to extend the duration of exclusive breastfeeding from the previous four to six months of age to a full six months. In 2004, Health Canada [2] and in 2005, the Canadian Pediatric Society and Dietitians of Canada [3] also updated recommendations on exclusive breastfeeding, defined as feeding only breast milk, which excludes water, breast milk substitutes, other liquids, and solid foods [4]. This affects the introduction of complementary feeding, defined as "the period during which other foods or liquids are provided along with breast milk" [5]. Within Canada, there have been reports published on food intake patterns for infants in Vancouver [6], Ottawa [7], Quebec [8, 9], Newfoundland [10] and New Brunswick [11], but a national survey is lacking.

In the United States, the 2004 Feeding Infants and Toddlers Study (FITS) [12, 13] provides comprehensive data on the food and beverage patterns of infants. The FITS was a cross-sectional survey of more than 3,000 children aged four to 24 months, based on 24-hour dietary recalls. In 1983, the Heinz Company of Canada published a first attempt at a national survey [14]. Twenty years later, in 2003, Heinz commissioned an independent firm (LLS/DVR Market Research, Toronto, Canada) to conduct a market survey of Canadian infants. From this data, we report breastfeeding practices and complementary food consumption patterns of Canadian infants.

\section{MATERIALS AND METHODOLOGY}

In July 2003, a cross-sectional marketing survey was conducted on a nationally representative sample of mothers

\footnotetext{
*Address correspondence to this author at the H511 190 Dysart Road, University of Manitoba, Winnipeg, MB, R3T 2N2, Canada; Tel: 204-474-8682; Fax: 204-474-7593; E-mail: frielj@ms.umanitoba.ca
}

with infants aged three to 12 months. A total of 14,000 surveys (in English) were mailed to new mothers, selected from the Growing Family List, which consists of regularly updated parental information gathered from in-hospital sampling and prenatal education programs. The response rate was $21 \%$, providing data for a total of 2,951 infants. Although the response rate was low, the distribution of surveys was similar throughout the Atlantic region $(n=195)$, Quebec $(n=1,060)$, Ontario $(n=852)$, and the West $(n=844)$. After deleting incomplete records, 2,663 useful records remained. The survey consisted of three components: 1) a main questionnaire to assess demographic information, including breastfeeding practices and intentions; 2) assessment of consumer attitudes towards different infant foods; and 3) a four day food diary, for which a coded food list of 197 infant and table foods was provided. Food group categories were: Infant Cereals (by brand), Fruits, Vegetables, Meat, Poultry, Fish, Dairy (including eggs, yogurt, cheese, cow's and soy milk), Beverages, Desserts/Cookies/Sweets, Breads/Grains/ Cereals, Casseroles/Dishes, and Other Foods (potato chips, French fries, beans, tofu, and pizza). Respondents were asked to record every item that they fed their youngest child for four days (two weekdays and two weekend days). Each day allowed up to four eating occasions, classified by who was feeding, the time of day, and the feeding location. Each occasion allowed up to five dishes, composed of any number of different foods. Furthermore, each dish was classified by the quantity served (tablespoons) and the maximum volume per dish was set at 20 tablespoons. Also, all foods were classified by source: jarred, cereal, homemade, or store-bought. A four day diary and an extensive questionnaire were chosen to provide sufficient data for marketing trends and maintain a reasonable participant burden. Data were collected for a total of over 77,000 dishes and analyzed using Microsoft Excel software. Since this was a market survey generated to understand Canadian consumer habits, no ethical approval was sought. A fifteen dollar honorarium was provided as an 
Table 1. Primary Feeder During Infancy



incentive. Statistical analysis of the data consisted of description only.

\section{RESULTS}

\section{Demographics}

This report presents data for infants aged three to 12 months of age (Table 1). Of these infants, approximately $80 \%$ were fed by their mothers and most were fed at home (Table 1). Approximately $84 \%$ of all meals were consumed at home, $8 \%$ at another person's home, $3 \%$ in a public place, and $1 \%$ at work. Food diaries available at each month are listed in Table 1. Fifty-six percent of infants came from single-child families; $31 \%$ from two-child families, and $13 \%$ from families with three or more children. Sixty percent of mothers were 30 years of age or less and $40 \%$ were aged 30 years or more. At the time of study, $13 \%$ of mothers were employed full-time, $6 \%$ were employed part-time and the remaining $71 \%$ were on maternity leave. Twenty-three percent of mothers had completed an educational level of high school or less, $38 \%$ college or other, and 39\% were University educated. Combined family incomes per year were: $<45,000$ for $41 \%$ of all mothers; $45-60,000$ for $18 \%$ of all mothers; and $>60,000$ for $41 \%$ of all mothers.

\section{Breast Feeding Practices}

Participants were asked "Did you or do you breastfeed your baby?" Seventy-three percent of respondents indicated they had either initiated breastfeeding, or were currently breastfeeding, their youngest infant. By three months of age, $19 \%$ were exclusively breastfeeding. This proportion declined to $2 \%$ at four months. By six months no mother was exclusively breastfeeding.

\section{Complementary Foods}

Eighty-one percent of all infants were fed solid foods at three months of age. At four, five, and six months, $85 \%$, $89 \%$, and $100 \%$, respectively, were fed solids. The greatest volume of complementary food intake, as reflected in total tablespoons for all infants over four days, occurred in the morning (39,100 tablespoons) and was followed by dinner $(34,200$ tablespoons). Lunch and afternoon had similar intakes (26,700 and 25,500 tablespoons, respectively), followed by night-time (7,400 tablespoons) (Fig. 1). Sixty-two percent of total morning food intake was infant cereal, the major food consumed by Canadian infants at any time period.

At three months, $72 \%$ of all infant cereal intake was ricebased and $98 \%$ was plain (versus flavored). At six months,

Solid Volume

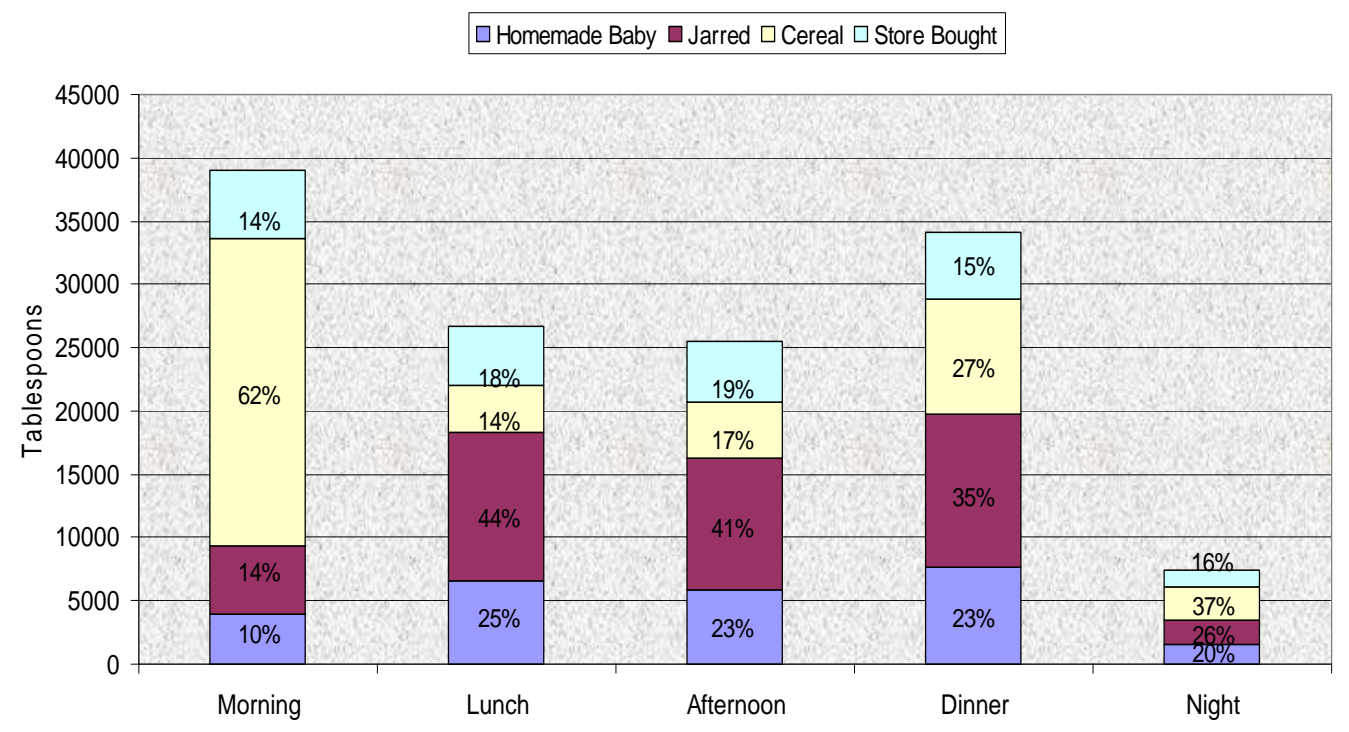

Fig. (1). Complementary food intake by time of day. 
Infant Cereal Volume Intake by Age

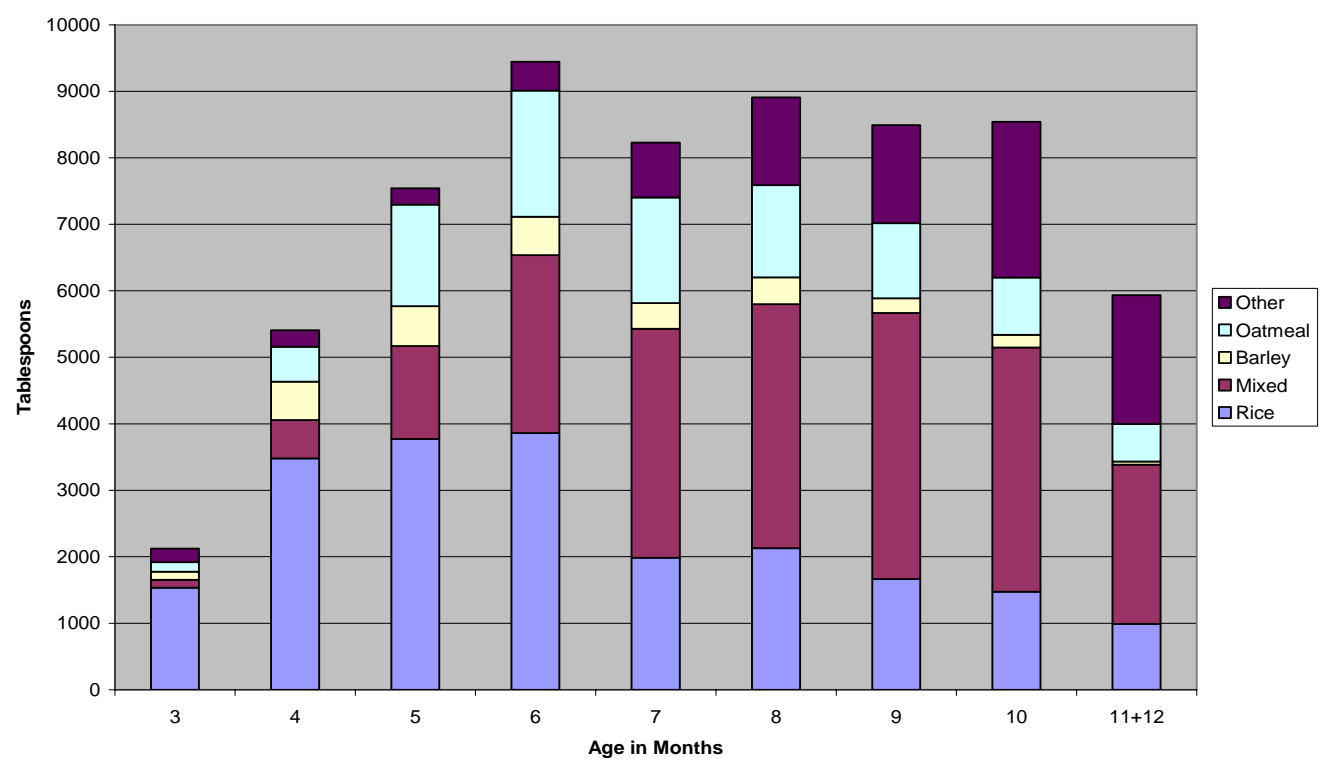

Fig. (2). Infant cereal volume intake by age.

rice cereal was still dominant, but mixed grain and oatmeal cereal had increased to $28 \%$ and $20 \%$ of total cereal consumption, respectively. By nine months, nearly half of all cereal volume was mixed grains $(47 \%)$ and flavored cereal (48\%) (Fig. 2).

The "top 20" single-food meals (excluding milk and cereal) were dominated by fruits and vegetables. Varieties of fruit increased with age. The top five single foods consumed from three to five months of age were banana, carrots, sweet potato, apple, and squash, respectively; and from six to eight months bananas, sweet potato, carrots, apple, and pear, respectively. By nine to 12 months, bananas and apples were still popular choices, but yogurt, Cheerios, and cheese had become included among the top five foods consumed.

At three months of age, infant cereal $(57.7 \%)$ and fruits and vegetables $(30.6 \%)$ provided the majority of complementary food volume (Fig. 3). By six months, these two groups were almost reversed, providing $32.4 \%$ and $53.0 \%$ of total volume, respectively. Fruit and vegetable volume peaked at six months of age (53\%) and then steadily declined with age, reaching a volume at 11 to 12 months (35\%) that was similar to that at three months $(30.6 \%)$. Meat $(1.8 \%)$, dairy $(2.9 \%)$, and bread $(1.5 \%)$ products were introduced as early as 3 months of age. By 11 to 12 months of age, infant

Percent Total Consumption by Food Categories

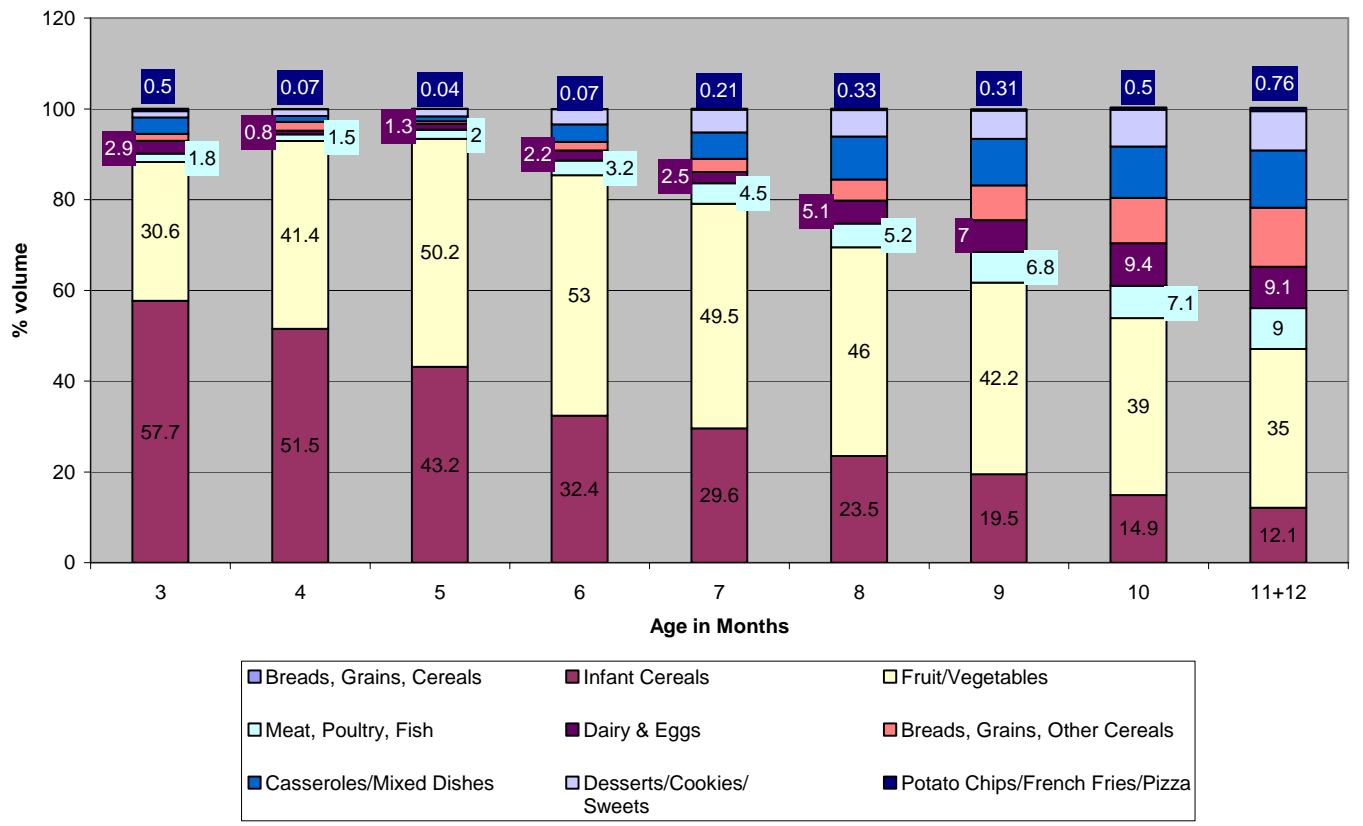

Fig. (3). Percent volume intake by food categories over 12 months. 
cereal, breads and grains, and mixed dishes contributed similar proportions to complementary food intake (12-13\%). Likewise, meat, dairy, and dessert intakes were similar at 11 to 12 months $(9 \%)$. There was a steady increase in "extra" foods, such as pizza, French fries and sweets, from three to $11 / 12$ months.

Solid food intake steadily increased with age (Fig. 4). For Canadian infants, cereals and fruits and vegetables appear to be the main food groups consumed from three to 12 months of age. By 11 to 12 months, homemade and store-bought foods made up more than half $(58 \%)$ of total food volume. Mothers indicated on the questionnaire that, by nine to 12 months, they began the transition to table foods because they felt guilty serving jarred baby foods.

\section{DISCUSSION}

This study was originally designed as a marketing survey with a focus on general trends of food consumption rather than nutrient intake assessment. The relatively low response rate provided sufficient data for a market assessment and dietary information about Canadian infants that is not available nor been reported elsewhere. The sample size is also considerably larger than followed in other Canadian studies $[6-11,14]$. Heinz Canada agreed to share this information in order to provide data on feeding patterns of Canadian infants.

\section{Breast Milk}

Health Canada [4] promotes breastfeeding as the optimal method for infant feeding since it provides the most favorable nutritional, immunological and emotional benefits for the development and growth of infants, In addition, exclusive breastfeeding until six months of age has been shown to be protective against gastrointestinal infections [15]. While it is evident that breastfeeding is the best choice for infant feeding, there is also evidence that various barriers may inhibit or even prevent this choice. Mothers have identified lack of support, fatigue, lack of confidence, early breastfeeding problems such as latching and sucking, and returning to work or school as obstructions to breastfeeding or continuation thereof $[16,17,18]$. Conversely, support from clinicians, nurses and spouses/partners has been shown to facilitate continuation of breastfeeding [16].

Current strategies and public health initiatives to implement the new recommendation to increase the length of breastfeeding include the Baby Friendly Initiative in hospitals [19], the Canadian Prenatal Nutrition Program [16], Dieticians of Canada, and the Expert Advisory Panel for Exclusive Breastfeeding [2]. Also, the Healthy People Initiative 2010 aims to increase the proportion of breastfed infants to ensure $75 \%$ are breastfed to some extent, $50 \%$ are breastfed for at least six months (with $25 \%$ receiving breast milk exclusively), and $25 \%$ are breastfed until one year of age. [19].

Reports from Moncton, New Brunswick [11] and the Monteregie region of Quebec [8] show higher breastfeeding initiation rates $(83 \%$ and $80 \%$, respectively) than those identified in this study (73\%). In 1983, Yeung [14] reported initiation rates of $71 \%$ for Canadian mothers, whereas the results from the 2003 Canadian Community Health Survey [20] indicated national initiation rates of $85 \%$. The Ross Mothers Study [21] conducted in the United States in 2006 , reported initiation rates of $70.1 \%$.

In a comparison of breastfeeding initiation rates between Canada, United States, Europe and Australia, the latter two countries reported rates of 74-99.5\% (Europe) and 91-97\% (Australia), while rates in Canada and the United States were lower (69-83\% and 27-69.5\%, respectively) [22]. The initiation rates in the current study fell within a similar range to other areas of Canada (73\%).

\section{Complementary Foods}

The WHO's recommendation to extend breastfeeding was based on a review that concluded that infant morbidity

\section{Solid Food Volume}

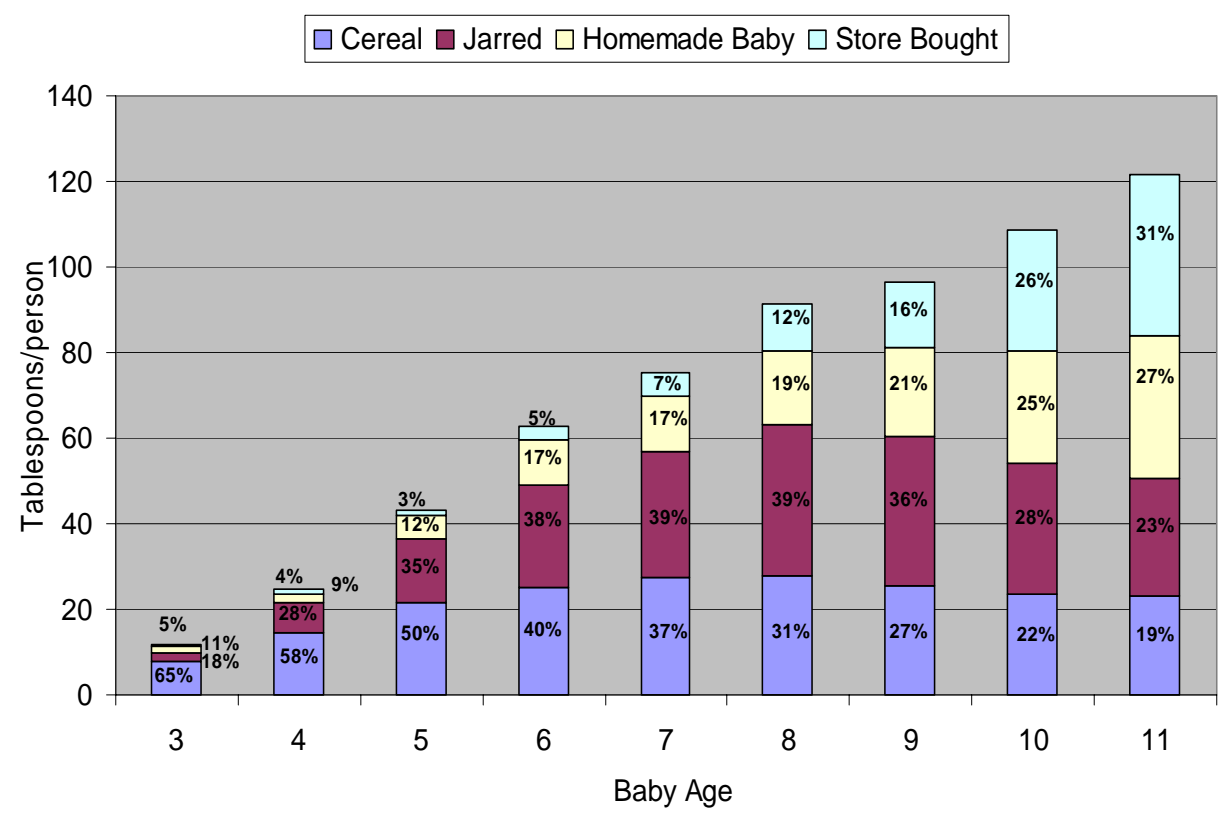

Fig. (4). Sources of complementary foods (tbsp) by month (\% of total volume). 
rates from gastrointestinal infection were lower when infants were exclusively breastfed for a full six months rather than for only three to four months [23]. Some have questioned whether sufficient evidence was available [24] to make this new recommendation. In addition, WHO suggested that complementary foods be first introduced at six months of age and that breastfeeding be continued thereafter [25]. Opinions vary as to the suitability of this global recommendation, particularly for developed countries [26, 27]. In 2005, the updated recommendations in Canada's Nutrition for Healthy Term Infants [3] suggested that iron-rich foods, such as iron-fortified infant cereals and meats, be introduced at six months due to concerns about iron and zinc status [6, 28, 29].

The American Academy of Pediatrics [30] recommends that complementary foods be introduced at four to six months of age. The AAP [30] also recommends that infants be exclusively breastfed during the time preceding the introduction of solid foods and that breastfeeding be continued until at least 12 months of age.

In recent years, researchers have further investigated the best timing for introduction of complementary foods. Poole and colleagues [31] reported that children who were first exposed to cereals after six months had an increased risk of wheat allergy compared with those first exposed before six months of age. Agostoni et al. [32] reviewed the evidence and concluded that complementary feeding should not be initiated prior to 17 weeks of age, but should be started no later than 26 weeks of age. Krebs et al. [33] suggested that pureed meat should be introduced as the first complementary food.

Data from the current study suggests that most Canadian infants consume iron-fortified cereal as their first solid food. Infants in the current study were introduced to solid foods at least as early as three months of age. Complementary foods consisted mostly of infant cereals (where rice cereal predominated), fruits, and vegetables and, to a lesser extent, dairy products, meat, fish, poultry, breads, grains, and desserts. Other researchers in Canada $[7,11]$ have indicated that infant cereals were introduced at or before four months of age, and US investigators [12] reported that infant cereals, as well as fruits and vegetables, were being consumed at four months of age. In both the current and FIT [12] studies, the most popular fruits and vegetables consumed at four months were carrots, sweet potatoes, apples, and bananas. Thus, the Canadian infants surveyed by Heinz in 2003 were following the traditional guidelines at that time for the introduction of solid foods: consuming primarily infant cereals first, followed by fruits and vegetables, and finally, meat and dairy [3].

The recommended consistency for solid foods at six months is generally in the pureed form. Later, 'finger foods' can be introduced at eight months and 'family foods' at 12 months [1, 34]. However, Rapley [34] argues that the introduction of pureed food could delay the development of chewing skills. In the current study, three- to five-month old infants were fed mostly (85\%) infant cereals and jarred baby foods, which was consistent with the WHO's recommendation to introduce pureed foods first [25]. However, the introduction of solid foods at or before three months is inconsistent with the guidelines [3, 25]. By extending exclusive breastfeeding and delaying the introduction of solid foods, traditional foods and feeding patterns may no longer be sufficient to meet new recommendations. This is particularly true for iron needs that, in Canada, have always been met by the consumption of iron-fortified cereals in early infancy. Iron needs may now be met by non-iron-fortified foods, particularly iron-rich meats [33].

The types of foods purchased and prepared by mothers changed with the age of their infant. As infants approached one year of age, more homemade foods were given. In other words, table foods were replacing prepared baby foods (Fig. 4). Several studies have been published regarding the physiological readiness of infants for the consumption of solid foods [36, 37]. Developmental milestones are broad and the stages of development are unique to each infant. Will the new feeding guidelines change the pattern of solid food intake among Canadian infants? Will more infants be at risk for iron deficiency due to decreased iron stores and a later introduction of iron-rich foods? Is it reasonable to advocate that an infant's first foods should be meat $[1,3]$ rather than iron-fortified cereals, even though the Cancer Society [38] recently recommended that adults reduce their consumption of red meat? In order to address these issues, a new survey is needed to assess the affect of the new feeding guidelines on food patterns relative to those observed in 2003.

The current study is limited in that the database consists of convenience data, collected by Heinz for marketing purposes only. However, these data are not available from any other source. They provide a window into Canadian infant feeding patterns.

\section{CONCLUSION}

Complementary feeding in Canada, in 2003, started at approximately three months of age for many infants, where infant cereal predominated and was introduced first. Other foods including fruits, vegetables, meats, and dairy products were introduced later. The new recommendations for breastfeeding are likely to affect the patterns of complementary food consumption. Future studies could repeat the current protocol in order to assess changes in the patterns of feeding for Canadian infants that may occur due to the new extended feeding recommendations for breastfed infants.

\section{ACKNOWLEDGEMENTS}

Funding support was received from CIHR and Heinz Canada. Jennifer Jamieson helped prepare the data for interpretations as well as contributing to the manuscript. Daniel Prowse and Sara Simmons provided their expertise in database creation. We also thank all parents who took part in the survey.

\section{REFERENCES}

[1] World Health Organization. Global strategy for infant and young child feeding, the optimal duration of exclusive breastfeeding. Geneva, Switzerland: World Health Organization; 2003 [Cited 2007 Oct 25]. Available from: http: //www.who.int/nutrition/publications/infantfeeding/en/index.html

[2] Health Canada. Exclusive breastfeeding duration - 2004 Health Canada Recommendation. Ottawa, ON: Health Canada; c2004 [Updated 2008 Jan 7; Cited 2008 Jan 25]. Available from: http: //www.hc-sc.gc.ca/fn-an/nutrition/child-enfant/infantnourisson/excl_bf_dur-dur_am_excl_e.html 
[3] Health Canada. Nutrition for Healthy Term Infants - Statement of the Joint Working Group: Canadian Paediatric Society, Dietitians of Canada and Health Canada [monograph on the internet]. Ottawa: Minister of Public Works and Government Services; 2005 [Cited 2007 Oct 20]. Available from: http: //www.hc-sc.gc.ca/fnan/pubs/infant-nourrisson/nut_infant_nourrisson_term_e.html

[4] Health Canada. Nutrition for a healthy pregnancy: National guidelines for the childbearing years [monograph on the internet]. Ottawa: Minister of Public Works and Government Services; 1999 [Cited 2007 Oct 20]. Available from: http: //www.hc-sc.gc.ca/fnan/nutrition/prenatal/national_guidelines-

lignes_directrices_nationales-05-eng.php

[5] World Health Organization Division of Nutrition/UNICEF. Complementary feeding of young children in developing countries: A review of current scientific knowledge. Geneva: World Health Organization 1998.

[6] Innis SM, Nelson CM, Wadsworth LD, MacLaren IA, Lwanga D. Incidence of iron-deficiency anaemia and depleted iron stores among nine-month-old infants in Vancouver, Canada. Can J Public Health 1997; 88(2): 80-4.

[7] Kwavnick BS, Reid DJ, Joffres MJ, Guernsey JR. Infant feeding practices in Ottawa-Carleton: The introduction of solid foods. Can J Public Health 1999; 90(6): 403-7.

[8] Haiek LN, Gauthier DL, Brosseau D, Rocheleau L. Understanding breastfeeding behavior: Rates and shifts in patterns in Quebec. J Hum Lact 2007; 23(1): 24-30.

[9] Willows ND, Dewailly E, Gray-Donald K. Anemia and iron status in Inuit infants from northern Quebec. Can J Public Health 2000; 91(6): 407-10.

[10] Friel JK, Andrews WL, Simmons BS, et al. Evaluation of full-term infants fed an evaporated milk formula. Acta Paediatr 1997; 86(5): 448-53.

[11] Rioux FM, Savoie N, Allard J. Is there a link between postpartum anemia and discontinuation of breastfeeding? Can J Diet Pract Res 2004; 67(2): 72-6.

[12] Fox MK, Pac S, Devaney B, Jankowski L. Feeding infants and toddlers study: What foods are infants and toddlers eating? J Am Diet Assoc 2004; 04(Suppl 1): S22-30.

[13] Skinner JD, Ziegler P, Pac S, Devaney B. Meal and snack patterns of infants and toddlers. J Am Diet Assoc 2004; 104(Suppl 1): S65S70.

[14] Yeung DL. Infant nutrition: A study of feeding practices and growth from birth to 18 months. 1st ed. Ottawa: The Canadian Health Public Health Association 1983.

[15] Kramer MS, Guo T, Platt RW, et al. Infant growth and health outcomes associated with 3 compared with 6 mo of exclusive breastfeeding. Am J Clin Nutr 2003; 78: 291-95.

[16] Hogan SE. Overcoming barriers to breastfeeding: Suggested breastfeeding promotion programs for communities in eastern Nova Scotia. Can J Public Health 2001; 92(2): 105-08.

[17] Bell L, Lacombe M, Yergeau E, et al. The factors facilitating and constraining the continuation of breastfeeding in women in Estrie (Quebec). Can J Public Health 2008; 99(3): 212-5.

[18] Taveras EM, Capra AM, Braveman PA, Jensvold NG, Escobar GJ, Lieu TA. Clinician support and psychosocial risk factors associated with breastfeeding discontinuation. Pediatrics 2003; 112 (Pt 1): $108-15$.

[19] Keister D, Roberts KT, Werner SL. Strategies for breastfeeding success. Am Fam Physician 2008; 78(2): 225-32.

[20] Millar WJ, Maclean H. Breastfeeding practices. Statistics Canada Health Statistics Division. Health Reports, Catalogue 82-003; 16(2): 5-33. Ottawa: Statistics Canada 2005.

[21] Ryan AS, Zhou W. Lower breastfeeding rates persist among the special supplemental nutrition program for women, infants, and children participants, 1978-2003. Pediatrics 2006; 17(4): 136-46.
[22] Callen J, Pinelli J. Incidence and duration of breastfeeding for term infants in Canada, United States, Europe and Australia: A literature review. Birth 2004; 31(4): 285-92.

[23] Kramer MS, Kakuma R. Optimal duration of exclusive breastfeeding. Cochrane Database Syst Rev 2002; 1: CD003517.

[24] Fewtrell MS, Morgan JB, Duggan C, et al. Optimal duration of exclusive breastfeeding: What is the evidence to support current recommendations? Am J Clin Nutr 2007; 85: 635S-8S.

[25] World Health Organization. Complementary feeding: Report of the global consultation and summary of guiding principles for complementary feeding of the breastfed child. Geneva, Switzerland: World Health Organization; c2001 [cited 2007 Nov 1]. Available from: http: //www.who.int/nutrition/publications/nComplementary_ Feeding.pdf

[26] Dewey KG. What is the optimal age for introduction of complementary foods? Nestle Nutr Workshop Ser Pediatr Prog 2006; 58: 61-70.

[27] Reilly JJ, Wells JC. Duration of exclusive breast-feeding: Introduction of complementary feeding may be necessary before 6 months of age. Br J Nutr 2005; 94(6): 869-72.

[28] Michaelsen K. What is known? Short-term and long-term effects of complementary feeding. In: .Schmitz HO Ed. Feeding during Late Infancy and Early Childhood: Impact on Health, Nestle Nutr Workshop Ser Pediatr Program. Nestec Ltd 2005; 56: 85-205.

[29] Chantry CJ, Howard CR, Auinger P. Full breastfeeding duration and risk for iron deficiency in U.S. infants. Breastfeed Med 2007; 2(2): 63-73.

[30] Poole JA, Barriga K, Leung DYM et al._Timing of initial exposure to cereal grains and the risk of wheat allergy. Pediatrics 2006 117(6): 2175-82.

[31] Agostoni C, Decsi T, Fewtrell M, et al. Complementary feeding: a commentary by the ESPGHAN Committee on Nutrition. J Pediatr Gastroenterol Nutr 2008; 46(1): 99-110.

[32] Krebs NF, Westcott, JE, Butler N, et al. Meat as a first complementary food for breastfed infants: Feasibility and impact on zinc intake and iron status. J Pediatr Gastroenterol Nutr 2006; 42(2): 20714.

[33] Dewey KG, Cohen RJ, Brown KH, Rivera LL. Effects of exclusive breastfeeding for four versus six months on maternal nutritional status and infant motor development: Results of two randomized trials in Honduras. J Nutr 2001; 131(2): 262-7.

[34] Rapley G. Baby-led weaning, a developmental approach to the introduction of complementary foods. In: Moran VH, Dykes F Eds. Maternal and infant nutrition and nurture: Controversies and challenges. London: Quay Books, Mark Allen Publishing Ltd. 2006: 275-98.

[35] Naylor AJ, Morrow AL Eds. Naylor, Morrow, and Goldman's. Developmental readiness of normal full term infants to progress from exclusive breastfeeding to the introduction of complementary foods: Reviews of the relevant literature concerning infant immunologic, gastrointestinal, oral motor and maternal reproductive and lactational development. Washington DC: Wellstart International 2001.

[36] Carruth BR, Ziegler PJ, Gordon A, Hendricks K. Developmental milestones and self-feeding behaviors in infants and toddlers. J Am Diet Assoc 2004; 104(1 Suppl 1): S51-6.

[37] World Cancer Research Fund/American Institute for Cancer Research. Food, Nutrition, Physical Activity, and the Prevention of Cancer: A Global Perspective. Washington, DC: American Institute for Cancer Research; 2007 [cited 2007 Oct 28]. Available from: http: //www.aicr.org/site/PageServer?pagename=res_report_second

[38] Kleinman RE. American Academy of Pediatrics recommendations for complementary feeding. Pediatrics 2000; 106(5): 1274. 